\title{
Atividade prática de energias alternativas como meio facilitador de ensino de Ciências para alunos da Educação de Jovens e Adultos (EJA)
}

\author{
Practical activity of alternative energies as a facilitating way of teaching the Sciences to \\ students of the Education of Youth and Adults (EYA)
}
Cícero Jefferson Turbano Ramalho ${ }^{1}$, Gilberto do Nascimento Gasparini ${ }^{1}$, Leandro Carbo $^{2}$
e André Berton ${ }^{3}$

\footnotetext{
${ }^{1}$ Graduado, Núcleo Avançado de Jaciara, Instituto Federal de Educação, Ciência e Tecnologia de Mato Grosso - Campus São Vicente, Jaciara, MT, Brasil.

${ }^{2}$ Doutor (professor), Núcleo Avançado de Jaciara, Instituto Federal de Educação, Ciência e Tecnologia de Mato Grosso Campus São Vicente, Jaciara, MT, Brasil.

${ }^{3}$ Graduado (professor), Núcleo Avançado de Jaciara, Instituto Federal de Educação, Ciência e Tecnologia de Mato Grosso Campus São Vicente, Jaciara, MT, Brasil.
}

\begin{abstract}
Resumo
O presente trabalho discorre sobre utilização de recursos didáticos alternativos como meio facilitador no processo de ensino aprendizagem de Ciências na modalidade Educação de Jovens e Adultos (EJA), enfatizando experimentos e uma gincana lúdica pedagógica, por meio de um método interacionista para construção de conhecimento e de um ser crítico com frequentes interações com objetos e o meio. Essa atividade foi realizada na Escola Municipal Magda Ivana, aos alunos do segundo segmento da EJA fundamental o que foi muito proveitoso, pois os mesmos aprenderam conceitos e práticas que os ajudaram a desenvolver atividades lúdicas pedagógicas, promovendo a interação e colaboração de todos.
\end{abstract}

Palavras-chave: Ciências. EJA. Energias alternativas. Atividades práticas. Aprendizagem.

\begin{abstract}
The present work discourses about the use of alternative teaching resources as a facilitating way in the teaching learning process of Sciences in the Education of Youth and Adults (EYA) modality, emphasizing experiments and a playful pedagogic gymkhana, by way of an interacionist method for the building of knowledge and of an analytical being with frequent interactions with objects and the environment. This activity was developed at Magda Ivana Municipal School, for the second segment fundamental EYA students which was very useful, for they learned concepts and practices that helped them to develop playful pedagogic teaching activities, promoting the interaction and collaboration of all.
\end{abstract}

Keywords: Sciences, EYA, Alternative Energies, Practical activities, Learning. 


\section{Introdução}

A Educação de Jovens e Adultos (EJA) é um caminho que promove a inserção de estudantes com baixa escolaridade no ensino público, para enfrentarem seus problemas mais graves, tais como pobreza extrema, marginalização social, uso de drogas, violência, subemprego, analfabetismo, gravidez precoce. Vários desses fatores influenciam na desistência desses alunos de cursarem o ensino regular nas fases e idades adequadas de sua vida escolar. No ensino fundamental, essa modalidade auxilia os cidadãos que não tiveram a oportunidade de cursar esse nível de escolaridade na idade adequada promovendo o aprendizado, a fixação e a qualificação permanente, auxiliando na autonomia dos alunos (BRASIL, 2002).

A disciplina de Ciências na EJA do ensino fundamental deve ser trabalhada de forma que haja constantes trocas de conhecimento, valores e opiniões entre alunos e professores para fixação de conteúdo. Para que isso ocorra, o professor deve usar da criatividade para aperfeiçoar suas aulas utilizando meios didáticos alternativos, com o intuito de obter uma interação positiva dos alunos. Entretanto, deve-se levar em consideração diversos fatores como o contexto social onde estão inseridos, conhecimentos prévios, dinâmica dos alunos, entre outros fatores para estabelecer um maior envolvimento dos mesmos no ensino de Ciências.

O simples ato de transmitir conceitos científicos não é o suficiente para garantir um ensino de ciências que seja capaz de contribuir para o desenvolvimento do aluno no sentido de que ele possa exercer de forma correta sua cidadania, muito menos para instigá-lo a ser um intelectual crítico. Para Freire (2010) esse tipo de educação denomina-se" bancária”, só serve para uma alienação e, ainda por cima, aumenta o sufoco provocado pela classe dominadora sobre a classe dominada.

O ensino para os estudantes da EJA merece uma atenção especial, por possuírem turmas heterogêneas, sendo boa parte de sua clientela formada por alunos com idades diferenciadas, pois possuem uma visão de mundo e conhecimentos prévios e vivências pessoais, por meio de experiências adquiridas. Segundo Oliveira (1999), o adulto vem com um histórico de muitas vivências, com habilidades e competências acumuladas e ideias sobre o mundo externo, sobre ele próprio e os demais. Na condição de ser inserido em circunstâncias de aprendizagem, nessa fase da vida em que se encontra, o adulto traz consigo várias habilidades e dificuldades (se comparando com a criança), e possivelmente maior capacidade de pensar sobre o conhecimento e seus próprios processos de aprendizagem.

O ensino de Ciências na EJA, ou em qualquer nível de ensino, seja ele formal ou não formal, deve ser um trabalho conjunto, onde ocorram relações constantes de trocas de conhecimentos, sendo de valores e opiniões entre professores, alunos e conteúdos curriculares abordados. O ensino de Ciências como abordado por Souza e Barros (2012) deve contribuir para o desenvolvimento do aluno em todos os âmbitos de sua vida e de sua realidade (escola, meio ambiente, sociedade).

O professor é como um guia no processo da educação devendo fazer o uso de diversos meios didáticos, com objetivo de alcançar uma interação positiva e construtiva entre o saber e a aprendizagem dos alunos nas aulas de ciências, considerando processos como a dinâmica dos mesmos, local onde estão inseridos e conhecimentos prévios. A didática como uma ciência que se fundamenta nos princípios da educação e se propõe a ajudar e educar o homem é uma ferramenta importante no contexto escolar, pois, é por meio dela, que se abrem possibilidades para o ensino (Sant'anna e Menegolla, 2002).

O livro didático é uma importante fonte de informação e serve de suporte para o ensino de Ciências, onde o professor pode e deve utilizar esse e outros recursos didáticos no processo de aprendizagem do aluno, entretanto a utilização desses dependerá das práticas abordadas pelo professor e do grau de interação dos alunos com os conteúdos estudados ministrados. Nesse sentido, os recursos abordados vêm de encontro com práticas diferenciadas de ensino, onde as teorias interacionistas, sendo de grande valia, afirmam que o conhecimento é obtido por meio da interação do sujeito e dos objetos de conhecimento, o que acarreta na organização e nas estruturas cognitivas do indivíduo.

A EJA, diferente das outras modalidades de ensino, possui uma classe bem heterogênea sendo que a 
maioria dos alunos são trabalhadores, pais, mães, de diversas classes, principalmente classe baixa, que tiveramobstáculos no processo de alfabetização, onde abandonaram a escola por um certo tempo e em seguida retomam os estudos, porem com pouca motivação, sem domínios e as habilidades de escrever ou interpretar (Fonseca, 2006). Diante desta realidade todos os professores precisam dar atenção especial aos alunos da EJA, o que deve acarretar em uma pratica docente diferenciada em relação aos alunos do ciclo regular.

Existem diversas práticas para ensinar ciências na EJA, dentre elas pode-se citar os jogos educativos, que são interativos e servem para auxiliar no processo ensino aprendizagem, uma vez que reforçam a assimilação dos conteúdos abordados em sala de aula. Dentro da área educação na EJA existem inúmeras práticas pedagógicas que facilitam o ensino, o professor usa da criatividade e dedicação para selecionar diversos recursos didáticos em sala, sejam eles filmes, documentários, jogos, músicas, charges, dentre outros, tudo isso com a finalidade de instruir e edificar conhecimentos em seus alunos.

Os jogos como recursos didáticos alternativos, auxiliam no processo de ensino aprendizagem de forma positiva, pois fazem com que os alunos interajam e se descontraiam colocando a mente em funcionamento para obter novos conhecimentos, esse tipo de recurso integra aluno e professor. Conforme relatado por Macedo et al, (2000), firmando uma relação entre jogo e conhecimento, pode-se assegurar que, para adquirir conhecimento e jogar é preciso agir.

Além dos jogos, outra proposta para a assimilação de conteúdos, principalmente na área de ciências, é a realização de gincanas que viabilizam o entrosamento de jovens e adultos, com isso tornase fácil a realização de atividades despertando a criatividade em todos.

Os estudantes da modalidade EJA devem ter acessibilidade ao conhecimento do ensino de ciências que condicionem os saberes necessários para aumentar sua capacidade crítica construtiva para melhorar a comunidade local e, posteriormente, auxiliar o mundo com ideias e práticas ecologicamente corretas, como é o caso das energias alternativas. Existem várias formas de energias alternativas, e que por meio de pesquisas e investimentos nesta área, tecnologias são desenvolvidas de maneira a aumentar a capacidade da produção sem agredir o meio ambiente. Buscando soluções inteligentes e viáveis e menos poluentes, com o maior ganho energético e o maior custo benefício.

Dentro do conceito de energias alternativas procura-se práticas que degradem o mínimo possível o meio ambiente, não afetando assim a renda e a produção econômica. Busca-se nas mais diversas fontes e literaturas os tipos mais viáveis de energias com o custo/benefício otimizado.

Em experimentos simples busca-se alternativas viáveis para desenvolver a temática e auxiliar na construção de conhecimento, isso de maneira lúdica e de prático acesso ao público jovem e adulto. Como reforça Freire (1997), os experimentos servem para entender a teoria e poder praticar, vivenciando isso os alunos são capazes de desenvolver seu conhecimento.

Diante do exposto, o objetivo do trabalho foi o desenvolvimento de uma atividade prática de energias alternativas para alunos da EJA como meio facilitador de assimilação de conteúdos de Ciências.

\section{Metodologia}

\subsection{Local de Desenvolvimento do Trabalho e Público Alvo}

A atividade foi realizada na Escola Municipal Magda Ivana, situada no bairro Jardim Aeroporto na Avenida Zé de Bia, s/n, limite da zona urbana com a zona rural, na cidade de Jaciara, Mato Grosso, ali são ofertados ensino fundamental regular nos períodos matutino e vespertino e no noturno a modalidade EJA fundamental (primeiro e segundo segmentos).

Assim, a intervenção foi proposta ao segundo segmento da EJA fundamental, que englobam o oitavo e nono ano, relacionando com alguns conteúdos trabalhados, principalmente no segundo semestre do presente ano. 


\subsection{Preparação da intervenção e seleção dos experimentos}

Os professores num contexto geral estão gradativamente habituando em suas aulas alguns experimentos de fácil execução, para assimilação dos conteúdos ministrados. Diante desse contexto foi pensado em uma oficina pedagógica, visando facilitar a aprendizagem por meio de experimentos, que podem ser montados por professores e alunos em sala de aula, com objetos e materiais que são comuns no cotidiano.

De acordo com o conteúdo de ciências, diversos experimentos poderiam ter sido feitos, porém escolheu-se os de fácil assimilação e praticidade em sala de aula, produzido com materiais encontrados facilmente sendo eles de baixo custo, entre esses, um experimento sobre energia eólica, um experimento com uma calculadora e dois limões unindo prática com teoria na área química englobando o tema de oxirredução, e uma gincana lúdica como instrumento pedagógico para favorecer o raciocínio lógico e desenvolver conhecimento.

A oficina foi elaborada com tempo previsto de duração em torno de uma hora e meia, mas para tal feito foram elaborados e testados todos os experimentos realizados na oficina. A intervenção pedagógica proposta no presente trabalho realizou-se no dia 30 de agosto de 2013 com 13 alunos em sala de aula.

De forma a auxiliar a atividade proposta, foram elaborados dois questionários, os quais foram aplicados em momentos diferentes da atividade, um no início, para avaliar o conhecimento dos alunos quanto aos assuntos que seriam abordados na oficina, e num segundo momento um questionário final, de forma a analisar os conhecimentos construídos após a realização da oficina.

\subsection{Procedimentos dos experimentos}

\subsubsection{Energia Eólica}

A energia eólica é uma forma indireta de obtenção de energia do sol, já que os ventos existem graças ao aquecimento desproporcional pelos raios solares da superfície da Terra. Para exemplificar a mesma, foi desenvolvido um experimento por meio de um cooler de computador que representaria um micro aerogerador, um secador de cabelos representando o vento, e por último um pequeno led de três volts.

\subsubsection{Calculadora}

Colocou-se um prego galvanizado (zinco), espetado numa parte do limão e em seguida foi feito a mesma coisa com uma moeda de 0,05 centavos (com uma camada de cobre) em outra parte do limão. Utilizou-se pequenas garras de jacaré ligadas ao fio de cobre para conectar um polo da calculadora de 1,5 volts ao prego e o outro polo da calculadora a moeda e consequentemente a ligou.

\subsubsection{Gincana Lúdica Pedagógica}

A gincana lúdica foi realizada seguindo regras para facilitar o desenvolvimento e fornecer aos alunos materiais para praticar, interpretar conteúdos de ciências. Um roteiro foi elaborado para determinar a sequência didática, onde a sala foi dividida em duas equipes. Em seguida, foi indicado um voluntário de cada equipe que representou nas atividades propostas em que cada um escolheu aleatoriamente elementos dispersos a mesa, um por vez em alternância para representar sua equipe.

Cada etapa vencida resultou na soma de um ponto. Primeiramente foi feito uma ligação em serie com cinco, depois quatro e por ultimo três elementos (frutas e objetos), onde o grupo vencedor foi aquele que conseguiu a maior voltagem, medida pelo multímetro. Consequentemente a equipe que obteve o maior número de pontos ao final da gincana consagrou-se vencedora. 


\section{Resultados e discussão}

\subsection{Organização e Testes dos Experimentos}

Para desenvolver a intervenção, diversos experimentos relacionados com o conteúdo de ciências foram verificados, de forma a promover a interação dos alunos com materiais simples do cotidiano, sendo de baixo custo e que atraem a atenção dos expectadores. Reforçando esse pensamento, as teorias do construtivismo onde indivíduo aprende de acordo com um processo ativo de interação contínua e trocas com o meio (Piaget, 2005), e a teoria em que o indivíduo aprende com suas interações sociais (Vygotsky, 2007), o que embasou a escolha e o processo de como deve ser a intervenção e os experimentos. Após análise, foi optado em seguir um paradigma construtivista, como reforçado por Lincoln e Guba (2006), explorando concepções sobre ensinar e aprender ciência e idéias sobre como ensinar ciência para alunos da EJA.

De forma a garantir o sucesso na realização do trabalho, foram realizados vários testes dos experimentos antes da atividade. Em relação ao experimento da calculadora, foram testadas várias frutas, porém com algumas não foi obtido sucesso. Depois de várias tentativas, descobriu-se a forma correta de ligação de todos os objetos envolvidos. Com isso evidenciou-se a maneira de realizar o experimento com sucesso na intervenção.

Em relação aos testes do experimento da energia eólica, primeiramente houve a tentativa com o secador de cabelo ligado a hélice do cooler para produzir energia suficiente para acendimento do led. Porém, o acendimento só foi possível quando usado um secador com potencia (1900w) suficiente para suprir a necessidade de velocidade das hélices do cooler.

\subsection{Experimentos de Energia Eólica e Calculadora}

O experimento da energia eólica foi uma atividade proposta à sala, para identificar na prática as teorias já conceituadas. O secador ao ser ligado produz vento que foi captado pelas hélices do cooler, que as fizeram girar em alta velocidade, transformando energia eólica em elétrica, que resultou no acendimento do led (Figura 01).

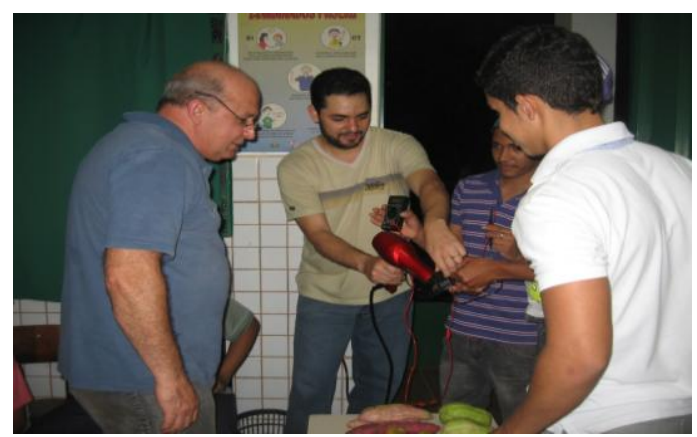

Figura 1 - Alunos observando o experimento da energia eólica

Observou-se a participação ativa dos alunos, o que despertou questionamentos por parte dos mesmos de como e onde obter energia eólica na natureza, sendo que ao final do experimento estes foram esclarecidos, de maneira que os próprios alunos entenderam a produção de energia eólica. Evidenciou-se nesse experimento o uso da prática construtivista do interacionismo, pois os alunos construiram conhecimento a partir de interações contantes com o meio.

"Ligando a calculadora com limões" foi o nome dado ao experimento que consistiu na exemplificação do conceito da oxirredução, como pode ser observado na Figura 02, ao qual houve o envolvimento dos alunos com o mesmo, demonstrando interesse na atividade proposta. Os estudantes ficaram surpresos com o experimento, pois grande parte não sabia que as frutas podiam transferir energia aos objetos a ponto de ligar uma calculadora substituindo as pilhas convencionais. $\mathrm{O}$ resultado do experimento tende ao fato de haver transferência de elétrons de um metal para o outro pelo meio ácido que é o limão (oxirredução). 


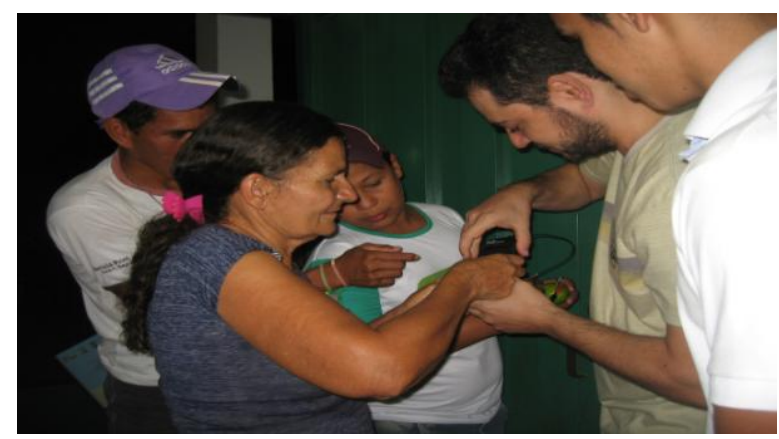

Figura 1 - Alunos realizando cálculos com a calculadora ligada por meio de limões

\subsection{Gincana elétrica}

A gincana elétrica foi elaborada para demonstrar de uma maneira prática e lúdica, por meio de brincadeiras, metodologias de ensino que visem à aprendizagem de forma descontraída e atraente. Procurou-se interagir com o público, com experimentos simples com frutas e objetos do cotidiano, de baixo custo e que podem atrair a atenção dos alunos.

A gincana, conforme pode ser observada na Figura 03, despertou interesse por ser uma novidade no contexto escolar em que esses alunos da EJA estão inseridos, porque essa modalidade de ensino segue os padrões tradicionais de aula, assim o livro didático, quadro negro e giz são as ferramentas mais utilizadas pelo professor. Fez com que os alunos aprendessem a trabalhar em equipe, verificando a vontade dos mesmos em participar da gincana, sendo que neste momento não houve dispersão deles para fora da sala.

Em um contexto geral, os alunos prestaram atenção e interagiram com os professores e colegas no desenvolvimento do experimento. Evidenciou-se nesse experimento o uso de dois paradigmas construtivistas, são eles, o interacionismo de Piaget, pois os alunos interagiram com o meio npara desenvolver conhecimento, e o segundo paradima contrutivista foi, o socio interacinismo de Vigotsky, pois os alunos trabalharam o social, ou seja eles tiveram que pensar em equipe para construir conhecimento.

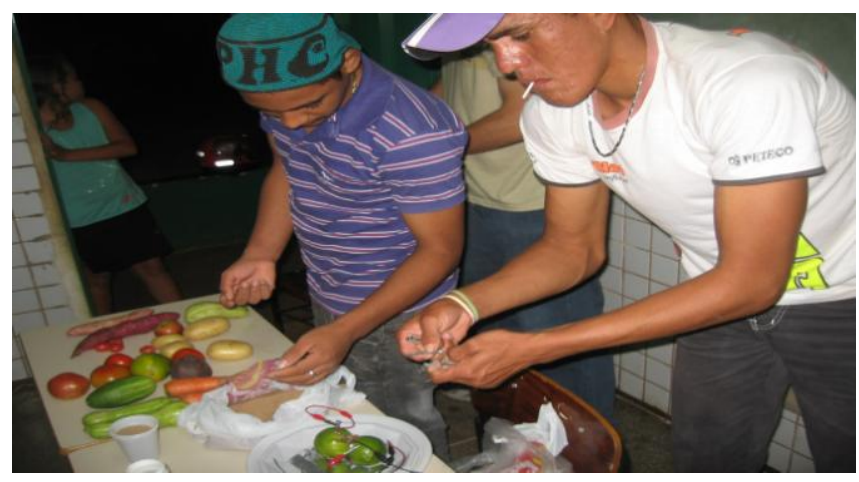

Figura 2 - Alunos participando e interagindo na gincana elétrica

\subsection{Percepção dos Alunos em Relação à Atividade Proposta}

Para mensurar os resultados e verificar a eficácia da intervenção realizada, com base nos questionários aplicados no início e fim da oficina, foram feitos algumas correlações entre as perguntas, para avaliar a aprendizagem dos alunos diante da atividade prática proposta.

Conforme observado na Figura 04, quando perguntado aos alunos o que eles entendiam por energia, antes da intervenção e feito um comparativo com a pergunta correspondente ao final da atividade, percebe-se que houve uma evolução conceitual dos alunos quanto ao tema abordado, evidenciando assim que a proposta pedagógica aplicada obteve sucesso na construção de conhecimento. 


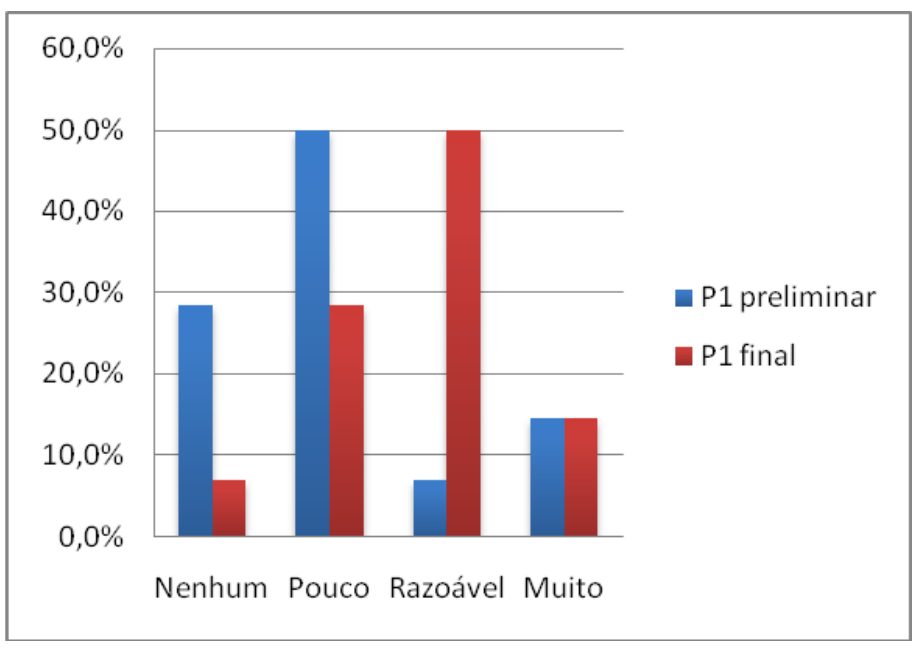

Figura 3 - Conhecimento dos alunos sobre energia, antes e após a realização da oficina

No questionário prévio demonstraram que $65 \%$ dos alunos não conheciam a temática ou ficaram receosos em responder e serem julgados por um possível erro tanto gramatical como interpretativo. Entretanto $35 \%$ dos alunos demonstraram ter algum conhecimento prévio, e descreveram com suas palavras, mesmo que de forma sucinta o que seria energia alternativa.

Ao comparar a terceira pergunta do questionário preliminar com a terceira do questionário final, notou-se que a maioria dos alunos não conseguiram descrever as definições do assunto abordado, pois não tinham conhecimento para isso. Porém ao fim da intervenção os mesmos estudantes que outrora desconheciam o tema, aprenderam conceitos e práticas que os ajudaram a desenvolver atividades lúdicas pedagógicas promovendo a interação e colaboração de todos.

\section{Conclusões}

O ensino de Ciências para a EJA é uma atividade desafiadora, porque a turma é geralmente heterogênea, constituída por estudantes de diferentes idades. E grande parte destes traz consigo muitas experiências de vida, saberes acumulados e reflexões sobre o mundo externo, tendo assim maior capacidade de reflexão sobre o conhecimento.

Diante disso, um ensino diferenciado é uma etapa importantíssima para alunos deste tipo de modalidade, tal como atividades práticas que relacionem o cotidiano dos mesmos com os conteúdos ministrados. Nesse contexto, a disciplina de Ciências possibilita inúmeras atividades pedagógicas, buscando relacionar a teoria e prática, prendendo assim a atenção dos alunos.

Nessa perspectiva, todos os experimentos realizados na sala de aula serviram de apoio na assimilação dos conceitos trabalhados, no caso energias alternativas. Os alunos ficaram maravilhados com as atividades realizadas, permanecendo o tempo de duração da oficina em sala, participando ativamente.

Logo após a intervenção, com os dados obtidos por meio dos questionários, verificou-se que houve evolução no aprendizado dos alunos, validando a prática de ensino por meio de experimentos interacionistas e sócio interacionistas.

\section{Agradecimentos}

Gostaríamos de agradecer aos alunos e profissionais da Escola Municipal Magda Ivana que prontamente aceitaram e colaboraram com as atividades desenvolvidas, e à Coordenação de Aperfeiçoamento de Pessoal de Nível Superior (CAPES) pelo subsídio através do Programa de Consolidação das Licenciaturas (PRODOCENCIA) Edital 019/2013, processo № 113.657, e do 
Programa Institucional de Bolsa de Iniciação à Docência (PIBID) Edital № 061/2013, processo № 128.570, IFMT/Campus São Vicente/Sub Projeto Ciências.

\section{Referências}

BRASIL. Ministério da Educação. Secretaria de Educação Fundamental. Educação de Jovens e Adultos. Ensino Fundamental: Proposta Curricular - 2º Segmento - 5 a $8^{\mathrm{a}}$ série. vol. 1. Brasília, 2002. Disponivel http://portal.mec.gov.br/secad/arquivos/pdf/eja/propostacurricular/segundosegmento/vol3 matematic a.pdf. Acessado em 14/08/2013.

FONSECA, M.C.F.R. A Educação Matemática e EJA. ConstruçãoColetiva:Contribuições à Educação de Jo vens e Adultos. Edições MEC /UNESCO, Brasília- F, junho, p 321, 2006

FREIRE, P. Pedagogia da Autonomia: Saberes Necessários À Prática Educativa. Rio de Janeiro: Paz e Terra, p 143, 1997.

FREIRE, P. Pedagogia do oprimido. 49ª Ed, Editora Paz e Terra, Rio de JaneiroRJ, p 213, 2010.

LINCOLN, Y. S.; GUBA, E. G. Controvérsias Paradigmáticas, Contradições E Confluências Emergentes. In DENZIN, N K,; LINCOLN, Y. S. 2. Ed. Porto Alegre: Artmed, p. 192, 2006.

MACEDO, Lino; PETTY, Ana L. S.; PASSOS, Norimar C. Aprender Com Jogos e Situações Problema. Porto Alegre: Artmed, p. 120, 2000.

OLIVEIRA, M. K. Jovens e adultos como sujeitos de ensino e aprendizagem. Revista Brasileirade Educação, n. 12, p.73, set/out/nov/dez. 1999.

PIAGET, J. A Linguagem e o Pensamento da Criança. 7. ed. Rio deJaneiro: Editora Fundo de Cultura p 307, 2005.

SANT'ANNA, Ilza Martins; MENEGOLLA, Maximiliano. Didática: Aprender a Ensinar- Técnicas e reflexões pedagógicas para formação de formadores. São Paulo: Loyola, p 126, 2002.

SOUZA, Pedro; BARROS, Marcelo. Jogos Interativos: Uma Possibilidade no Ensino De Ciências Para A Educação De Jovens E Adultos. III Encontro Nacional de Ensino de Ciências da Saúde e do Ambiente, Niterói, 2012. Disponível em www.ensinosaudeambiente.com.br/eneciencias/anaisiiieneciencias/trabalhos/T59.pdf.

VYGOTSKY, L. A Formação Social da Mente: O Desenvolvimento dos processos psicológicos superiores. 5 ${ }^{\mathrm{a}}$ ed. São Paulo: Martins Fontes, p 186, 2007. 